The 64th special issue "Frontiers of Carbon Materials"

\title{
Recent Development of Carbon-based Electrode for Vanadium Redox Flow Battery
}

\section{Risheng $\mathrm{LI}^{\mathrm{a}}$ and Yukari SATO ${ }^{\mathrm{a}, \mathrm{b}, *}$}

a Graduate School of Pure and Applied Sciences, University of Tsukuba, 1-1-1 Tennodai, Tsukuba, Ibaraki 305-8571, Japan

b Research Institute for Energy Conservation, National Institute of Advanced Industrial Science and Technology (AIST),

Central 5, 1-1-1 Higashi, Tsukuba, Ibaraki 305-8565, Japan

*Corresponding author: yukari-sato@aist.go.jp

\section{ABSTRACT}

Redox flow batteries (RFBs) can employ various carbon materials as electrodes. A carbon electrode must meet a number of requirements when RFBs are constructed. This short review focuses on carbon electrodes with desirable electrode materials for RFBs. They have attributes for active species that assist the construction of stable RFBs for long-term use, realize much higher energy densities, employ a wide range of active chemical redox materials, and achieve a total cost reduction for each of the different types and differently modified carbon electrodes. Here, we summarize recent approaches employed in the search for carbon materials and the development of methods for modifying carbon surfaces for RFBs.

(C) The Author(s) 2020. Published by ECSJ. This is an open access article distributed under the terms of the Creative Commons Attribution 4.0 License (CC BY, http://creativecommons.org/licenses/by/4.0/), which permits unrestricted reuse of the work in any medium provided the original work is properly cited. [DOI: 10.5796/electrochemistry.20-64076]. Uploading "PDF file created by publishers" to institutional repositories or public websites is not permitted by the copyright license agreement.

\section{Keywords : Redox Flow Battery, Carbon-based Electrode, Chemical Modification}

\section{Introduction}

Renewable energy sources such as wind-based and solar energy have attracted a lot of interest in recent decades. ${ }^{1}$ Redox flow batteries (RFBs) have received particular attentions as useful secondary batteries in comparison with traditional batteries thanks to their long cycle life, flexible design, and technical advances. ${ }^{2-7}$ RFBs offer excellent safety because most are constructed with nonflammable aqueous solutions, but the market for the RFB remains limited because of its low energy density and high cost. The energy density of an RFB can be improved by increasing the solubility of the electro-active species in the electrolytic solutions and activating the electrode surface. Most RFBs employ a carbon electrode, carbon-based electrodes (CEs), which are widely commercially available, can be divided into three main categories as regards material: carbon paper, carbon cloth and graphite felt. Carbon-based electrodes are extensively used in RFB systems due to their advantages, namely a large electrochemical specific surface area, low cost, high electronic conductivity and good acid resistance. However, the disadvantages of the $\mathrm{CE}$ such as poor wettability, poor kinetic reversibility and few active sites, reduce the energy efficiency of RFBs. Thus, many researchers have focused on modifying the $\mathrm{CE}$ to improve its electrochemical properties.

CE surfaces, which showed poor electrochemical activity for redox species such as vanadium ions, were improved to achieve excellent electrochemical performance. The electrochemical performance of CEs for RFBs depends on their physico-chemical properties. Surface wettability, surface area, and the flatness/atom level structure of surface are important matters. Surface functionality, surface modification, and the doping of other materials, such as a metal or metal oxide, are also essential when considering an ideal electrode for RFBs.

Here, we focus on recent CEs, which were improved by chemical/physical surface modification and that have technical and other specific features that allow them to achieve good performance for RFBs. This short review, mainly focuses on CEs for vanadium RFBs.

\section{Chemical Activations}

Table 1 summarizes the various surface modification/treatment methods applied to carbon-based electrodes to improve their surface properties.

Some of the approaches involve the deposition or direct growth of metal, ${ }^{8-12}$ metal oxide, ${ }^{13-21}$ and carbon-based nanomaterials on carbon materials. Various approaches employed with the carbonbased electrodes are also listed including thermal, chemical, doping, etching, and other techniques. The deposition and growth of metal $\left(\mathrm{Sn},{ }^{8} \mathrm{Ir},{ }^{9} \mathrm{Cu},{ }^{10} \mathrm{Bi}^{11,12}\right)$ and metal oxides $\left(\mathrm{MnO}_{2},{ }^{13} \mathrm{SnO}_{2},{ }^{14} \mathrm{Cr}_{2} \mathrm{O}_{3},{ }^{15}\right.$ $\mathrm{CeO}_{2},{ }^{16} \mathrm{TiO}_{2},{ }^{17} \mathrm{ZrO}_{2},{ }^{18} \mathrm{WO}_{3},{ }^{19} \mathrm{Nb}_{2} \mathrm{O}_{5},{ }^{20} \mathrm{NiCoO}_{2}{ }^{21}$ ) on a $\mathrm{CE}$ surface realized a noticeable enhancement as regards the kinetics of the vanadium redox reactions. For example, with a $\mathrm{MnO}_{2}$ nanosheet array modified CE, the number of active electrode sites increased the hydrophilicity of the electrode surface was improved. ${ }^{13}$ The introduction of $\mathrm{SnO}_{2}$ also improved the electrochemical performance of vanadium redox species because oxide particles exhibit notable hydrophilicity and promote new active sites. ${ }^{14}$ In another case, the introduction of, for example, $\mathrm{Cr}_{2} \mathrm{O}_{3}$ particles, led to hydrophilicity and higher activity and reversibility. ${ }^{15}$

With some of metal and metal oxide additions, the chemical stability of the electrode surface remains poor, and the introduction is not inexpensive. Carbon-based nanostructured materials include carbon nanofibers $(\mathrm{CNFs}),{ }^{22}$ carbon nanotubes $(\mathrm{CNTs}),{ }^{23-26}$ and graphene (graphene oxide, nanowalls), ${ }^{27,28}$ carbon nanosheets and nanorods. ${ }^{29}$ These modification, deposition and growth techniques with carbon nanomaterials introduce enhanced wettability, a much larger surface area, and higher conductivity for vanadium RFBs. However, these carbon-based structures are insufficient for the longterm operation of vanadium RFBs, and other activation challenges 
Table 1. Overview of carbon-based electrodes and modification methods for vanadium redox flow batteries.

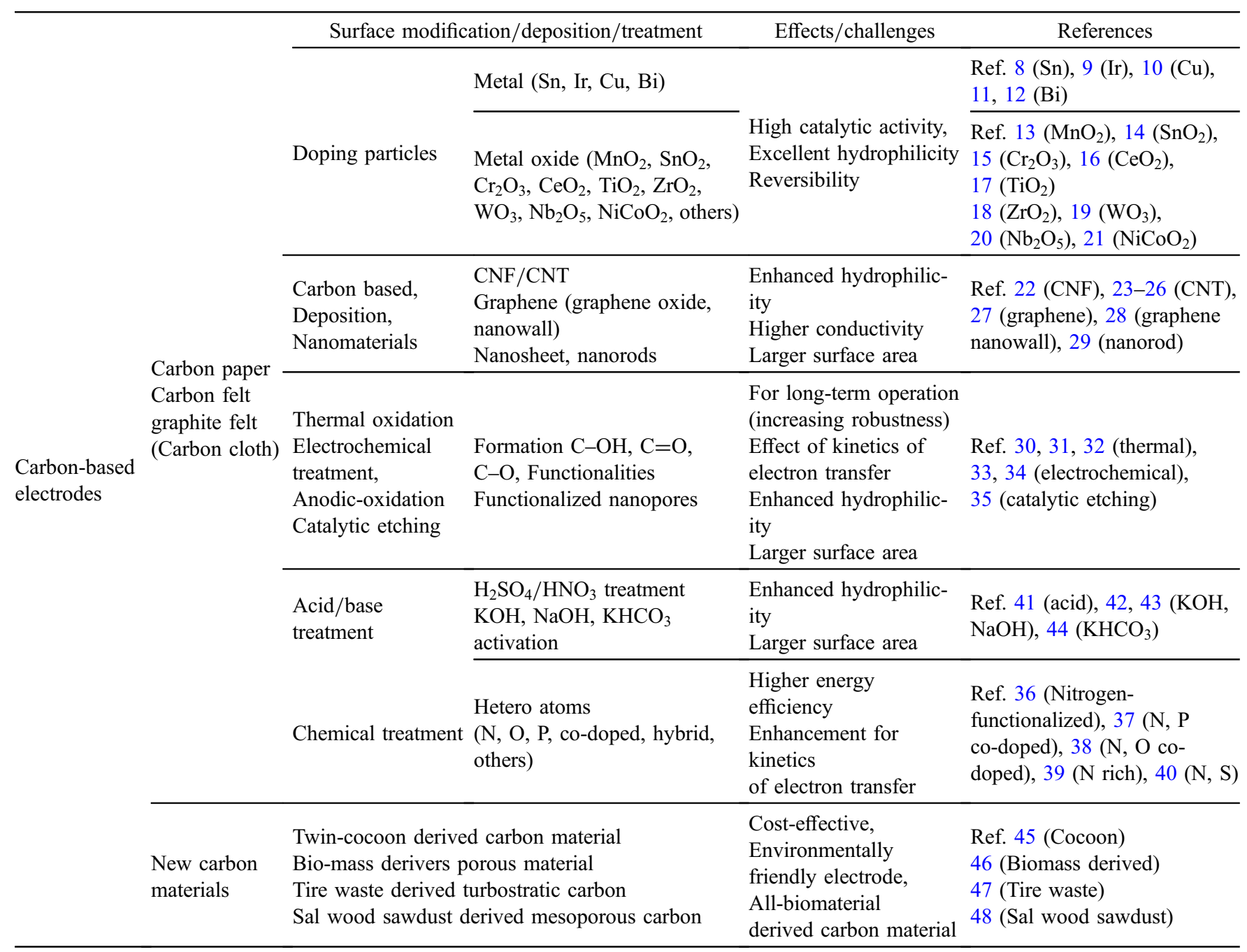

based on the thermal, ${ }^{30-32}$ electrochemical (anodic oxidation), ${ }^{33,34}$ and other techniques have also been reported recently.

The effect of the nitrogen functionalization of a graphite surface has also been reported. ${ }^{36} \mathrm{~N}$-functionalized graphite felt has more active sites, and the redox reaction of vanadium species has better reversibility. Nitrogen functionalization enhanced electrochemical properties by, for example, reducing both polarization and overpotential. An N-modified electrode improved the energy efficiency of a vanadium RFB (energy efficiency $75.5 \%$ at an N-modified electrode, whereas it was $69.2 \%$ with a normal electrode. ${ }^{35}$ An N, $\mathrm{P}-$, co-doping is an efficient strategy designed to improve the electrochemical kinetics of vanadium species with respect to both oxidation and reduction reactions. $\mathrm{N}$ and $\mathrm{P}$ heteroatoms function as active sites. ${ }^{37} \mathrm{~N}$ and $\mathrm{O}$ heteroatoms were also co-doped on the carbon electrode surface. ${ }^{38} \mathrm{~N}_{2}$ and $\mathrm{O}_{2}$ plasma was employed to treat carbon felt, and the electrocatalytic activity was improved. The energy efficiency of the vanadium RFB has been improved from $65 \%$ (pristine) to $78 \%$ ( $\mathrm{N}$ and $\mathrm{O}$ doped) at a current density of $50 \mathrm{~mA} \mathrm{~cm}^{-2}$. $^{38}$ The $\mathrm{N}$ and $\mathrm{O}$ co-doped carbon surface greatly improved the electrochemical performance of the battery thanks to the modified electronic properties and the enhanced affinity with the electrolyte. A three-dimensional designed network bridged with Nrich carbon film was designed and constructed and served as robust and high-efficiency electrodes for vanadium RFBs. ${ }^{39}$ In this case, the vanadium RFB can be operated with double the lifespan of a pristine electrode. Carbon nano-network wrapped carbon felt prepared with co-doped N, S exhibited long-term stability and efficient elec- trochemical performance. ${ }^{40}$ Acid or base treatments are also effective for the activation of the carbon electrode. ${ }^{41-44}$

Table 2 shows modification methods and the chemical and electrochemical properties of CEs.

Oxygen-rich functional groups, which were obtained by the addition of metal oxides, by coping with thermal/electrochemical oxidation and by other techniques, increase the active sites at which to redox reaction of vanadium species. ${ }^{13-15}$ The large surface area introduced by chemical treatment and the deposition of carbon nanomaterials are also enhanced reaction points for the vanadium species on the electrodes. ${ }^{22-29}$ In recent research, the optimal combination of thermally activated and nonactivated carbon felts in $\mathrm{VO}^{2+} / \mathrm{VO}_{2}{ }^{+}$ and $\mathrm{V}^{2+} / \mathrm{V}^{3+}$ redox couples showed the most efficient configuration. ${ }^{31}$ The electron transfer was found to occur by an inner-sphere process in $\mathrm{VO}^{2+} / \mathrm{VO}_{2}{ }^{+}$redox couple, whereas redox reaction of $\mathrm{V}^{2+} / \mathrm{V}^{3+}$ progressed an outer-sphere electron transfer. The required surface is different in the positive and negative electrolytes. ${ }^{31}$ Improvements to surface wettability/hydrophilicity and increasing the affinity between the vanadium redox species and electrodes are also expected to change the energy efficiency. ${ }^{36-40}$ As a consequence, higher performance vanadium RFBs will be realized.

\section{New Carbon Materials}

All-biomaterial-derived monolithic carbon materials have been developed. ${ }^{45}$ A cocoon, which is a protein-rich natural polymer fiber composite, can be easily obtained from the life cycle of a silkworm. 
Table 2. Modification methods and chemical, electrochemical properties.

\begin{tabular}{|c|c|c|c|c|c|c|c|c|c|}
\hline $\begin{array}{l}\text { Modification } \\
\text { Material/Method }\end{array}$ & Carbon & $\mathrm{R}_{\mathrm{S}} / \Omega$ & $\mathrm{R}_{\mathrm{CT}} / \Omega$ & $\mathrm{CE} / \%$ & $\mathrm{VE} / \%$ & $\mathrm{EE} / \%$ & Wettability & & \\
\hline $\mathrm{MnO}_{2}$ & $\begin{array}{l}\text { Carbon } \\
\text { paper }\end{array}$ & 1.43 & 0.30 & $97.0^{* 1}$ & $82.2^{* 1}$ & $75.6^{* 1}$ & $\begin{array}{l}\text { Water droplets } \\
\text { spread quickly }\end{array}$ & ${ }^{* 1}$ at $50 \mathrm{~mA} \mathrm{~cm}^{-2}$ & Ref. 13 \\
\hline $\mathrm{SnO}_{2}$ & $\begin{array}{l}\text { Carbon } \\
\text { paper }\end{array}$ & 1.13 & 10.5 & - & - & $86.1^{* 1}$ & $\begin{array}{l}\text { Contact angles: } \\
67.0^{\circ}\end{array}$ & & Ref. 14 \\
\hline $\mathrm{Cr}_{2} \mathrm{O}_{3}$ & $\begin{array}{l}\text { graphite } \\
\text { felt }\end{array}$ & 0.74 & 1.85 & $84.7^{* 2}$ & $80.9^{* 2}$ & $68.5^{* 2}$ & $\begin{array}{l}\text { Water droplets } \\
\text { spread quickly }\end{array}$ & $*^{2}$ at $100 \mathrm{~mA} \mathrm{~cm}^{-2}$ & Ref. 15 \\
\hline Graphene nanowall & $\begin{array}{l}\text { carbon } \\
\text { felt }\end{array}$ & 0.13 & 55.3 & $\sim 95^{* 3}$ & $\sim 95^{* 3}$ & $\sim 90^{* 3}$ & - & ${ }^{* 3}$ at $25 \mathrm{~mA} \mathrm{~cm}^{-2}$ & Ref. 28 \\
\hline N-rich carbon & $\begin{array}{l}\text { graphite } \\
\text { felt }\end{array}$ & $1.16 \pm 0.002$ & $1.82 \pm 0.31$ & - & - & $73.8^{* 4}$ & - & $* 4$ at $200 \mathrm{~mA} \mathrm{~cm}^{-2}$ & Ref. 39 \\
\hline $\mathrm{N}$-functionalized & $\begin{array}{l}\text { graphite } \\
\text { felt }\end{array}$ & - & - & $96.0^{* 5}$ & $89.8^{* 5}$ & $86.1^{* 5}$ & - & $* 5$ at $60 \mathrm{~mA} \mathrm{~cm}^{-2}$ & Ref. 36 \\
\hline $\begin{array}{l}\text { Nano-network } \\
\text { wrapped }\end{array}$ & $\begin{array}{l}\text { carbon } \\
\text { felt }\end{array}$ & 0.065 & 0.020 & $\sim 97^{* 6}$ & $\sim 95^{* 6}$ & $\sim 92^{* 6}$ & $0^{\circ}$ & ${ }^{* 6}$ at $80 \mathrm{~mA} \mathrm{~cm}^{-2}$ & Ref. 40 \\
\hline $\begin{array}{l}\mathrm{KHCO}_{3} \\
\text { activated }\end{array}$ & $\begin{array}{l}\text { carbon } \\
\text { microsphere }\end{array}$ & 6.97 & 0.16 & $\sim 90^{* 7}$ & $\sim 86^{* 7}$ & $\sim 77^{* 7}$ & $25^{\circ}$ & ${ }^{* 7}$ at $60 \mathrm{~mA} \mathrm{~cm}^{-2}$ & Ref. 44 \\
\hline
\end{tabular}

(Rs: Ohmic resistance, Rct: Charge transfer resistance, CE: Coulombic efficiency, VE: Voltage efficiency, EE: Energy efficiency).

Other new ideas, namely CEs derived from bio-mass (porous graphitic carbon), ${ }^{46}$ tire waste (turbostratic carbon), ${ }^{47}$ and Sal wood sawdust (mesoporous carbon) ${ }^{48}$ are also efficient electrodes for vanadium RFBs. These CEs have attracted particular attention in the energy storage field because of their diversity, environmentally friendly materials, and cost performance.

CEs were improved by chemical and physical modification and were provided with specific features to achieve good performance with vanadium RFBs. We also plan to focus on membranes and redox species for a new generation of RFBs.

\section{Acknowledgment}

This review is published with the recommendation of the Energy Forum of ECSJ, based on a submission request from the authors.

\section{References}

1. S. Wang, K. A. Owusu, L. Mai, Y. Ke, Y. Zhou, P. Hu, S. Magdassi, and Y. Long, Appl. Energy, 211, 200 (2018).

2. C. J. Rydh, J. Power Sources, 80, 21 (1999).

3. L. Joerissen, J. Garche, C. Fabjan, and G. Tomazic, J. Power Sources, 127, 98 (2004).

4. M. Skyllas-Kazacos, M. H. Chakrabarti, S. A. Hajimolana, F. S. Mjalli, and M. Saleem, J. Electrochem. Soc., 158, R55 (2011).

5. B. Hu, C. DeBruler, Z. Rhodes, and T. L. Liu, J. Am. Chem. Soc., 139, 1207 (2017).

6. Z. Wei, J. Zhao, D. Ji, and K. J. Tseng, Appl. Energy, 204, 1264 (2017).

7. M. Messaggi, P. Canzi, R. Mereu, A. Baricci, F. Inzoli, A. Casalegno, and M. Zago, Appl. Energy, 228, 1057 (2018).

8. S. Mehboob, A. Mehmood, J. Y. Lee, H. J. Shin, J. Hwang, S. Abbas, and H. Y. Ha, J. Mater. Chem. A, 5, 17388 (2017).

9. W. H. Wang and X. D. Wang, Electrochim. Acta, 52, 6755 (2007).

10. L. Wei, T. S. Zhao, L. Zeng, X. L. Zhou, and Y. K. Zeng, Appl. Energy, 180, 386 (2016).

11. B. Li, M. Gu, Z. Nie, Y. Shao, Q. Luo, X. Wei, X. Li, J. Xiao, C. Wang, V. Sprenkle, and W. Wang, Nano Lett., 13, 1330 (2013).

12. H. R. Jiang, Y. K. Zeng, M. C. Wu, W. Shyy, and T. S. Zhao, Appl. Energy, 240, 226 (2019).

13. Y. Jiang, X. Feng, G. Cheng, Y. Li, C. Li, Z. He, J. Zhu, W. Meng, H. Zhou, L. Dai, L. Dai, and L. Wang, Electrochim. Acta, 322, 134754 (2019).

14. X. He, Z. He, Q. Zou, and L. Wu, Int. J. Energy Res., 44, 2100 (2020).

15. Y. Xiang and W. A. Daoud, Electrochim. Acta, 290, 176 (2018).

16. H. Zhou, J. Xi, Z. Li, Z. Zhang, L. Yu, L. Liu, X. Qiu, and L. Chen, RSC Adv., 4, 61912 (2014)

17. Z. He, M. Li, Y. Li, J. Zhu, Y. Jianh, W. Meng, H. Zhou, L. Wang, and L. Dai,
Electrochim. Acta, 281, 601 (2018)

18. H. Zhou, Y. Shen, J. Xi, X. Qiu, and L. Chen, ACS Appl. Mater. Interfaces, 8, 15369 (2016).

19. M. Faraji, A. Hassanzadeh, and M. Mohseni, Thin Solid Films, 642, 188 (2017).

20. B. Li, M. Gu, Z. Nie, X. Wei, C. Wang, V. Sprenkle, and W. Wang, Nano Lett., 14, 158 (2014).

21. Y. Xiang and W. A. Daoud, J. Mater. Chem. A, 7, 5589 (2019).

22. M. Park, Y. J. Jung, J. Kim, H. I. Lee, and J. Cho, Nano Lett., 13, 4833 (2013).

23. Q. Li, A. Bai, Z. Qu, T. Zhang, J. Li, X. Zhang, M. Yu, Z. Xue, and H. Sun, J. Chem., 2019, 3258342 (2019)

24. I. Mustafa, R. Susantyoko, C. H. Wu, F. Ahmed, R. Hashaikeh, F. Almarzooqi, and S. Almheiri, Sci. Rep., 9, 17655 (2019).

25. W. Lee, B. W. Kwon, and Y. Kwon, ACS Appl. Mater. Interfaces, 10, 36882 (2018).

26. G. Wei, C. Jia, J. Liu, and C. Yan, J. Power Sources, 220, 185 (2012).

27. Z. González, C. Flox, C. Blanco, M. Granda, J. R. Morante, R. Menéndez, and R. Santamaría, J. Power Sources, 338, 155 (2017).

28. W. Li, Z. Zhang, Y. Tang, H. Bian, T. W. Ng, W. Zhang, and C. S. Lee, Adv. Sci. (Weinh), 3, 1500276 (2016).

29. S. Abbas, H. Lee, J. Hwang, A. Mehmood, H. J. Shin, S. Mehboob, J. Y. Lee, and H. Y. Ha, Carbon, 128, 31 (2018).

30. B. Sun and M. Skyllas-Kazakos, Electrochim. Acta, 37, 1253 (1992).

31. Y. Li, J. Parrondo, S. Sankarasubramanian, and V. Ramani, J. Phys. Chem. C, 123, 6370 (2019).

32. J. J. Park, J. H. Park, O. O. Park, and J. H. Yang, Carbon, 110, 17 (2016).

33. H. Kabir, I. O. Gyan, and I. F. Cheng, J. Power Sources, 342, 31 (2017).

34. W. Zhang, J. Xi, Z. Li, H. Zhou, L. Liu, Z. Wu, and X. Qiu, Electrochim. Acta, 89, 429 (2013).

35. S. Abbas, S. Mehboob, H.-J. Shin, O. H. Han, and H. Y. Ha, Chem. Eng. J., 378, $122190(2019)$

36. C. Youn, S. A. Song, K. Kim, J. Y. Woo, Y.-W. Chang, and S. N. Lim, Mater. Chem. Phys., 237, 121873 (2019).

37. Z. He, Y. Jiang, Y. Wei, C. Zhao, F. Jiang, L. Li, H. Zhou, W. Meng, L. Wang, and L. Dai, Electrochim. Acta, 259, 122 (2018).

38. Y. Huang, Q. Deng, X. Wu, and S. Wang, Int. J. Hydrogen Energy, 42, 7177 (2017).

39. H. Sheng, Q. Ma, J. G. Yu, X. D. Zhang, W. Zhang, Y. X. Yin, X. Wu, X. X. Zeng, and Y. G. Guo, ACS Appl. Mater. Interfaces, 10, 38922 (2018).

40. X. Zhang, Q. Wu, Y. Lv, Y. Li, and X. Zhou, J. Mater. Chem. A, 7, 25132 (2019).

41. B. Sun and M. Skyllas-Kazakos, Electrochim. Acta, 37, 2459 (1992).

42. J. Wang and S. Kaskel, J. Mater. Chem., 22, 23710 (2012).

43. E. Raymundo-Piñero, P. Azaïs, T. Cacciaguerra, D. Cazorla-Amorós, A. LinaresSolano, and F. Béguin, Carbon, 43, 786 (2005).

44. C. Zhao, Y. Li, Z. He, Y. Jiang, L. Li, F. Jiang, H. Zhou, J. Zhu, W. Meng, L. Wang, and L. Dai, J. Energy Chem., 29, 103 (2019).

45. R. Wang and Y. Li, J. Power Sources, 421, 139 (2019).

46. Y. Jiang, G. Cheng, Z. He, J. Chen, Y. Li, J. Zhu, W. Meng, H. Zhou, L. Dai, and L. Wang, J. Electrochem. Soc., 166, A3918 (2019).

47. R. Kumar, T. Bhuvana, and A. Sharma, ACS Sustainable Chem. Eng., 6, 8238 (2018).

48. M. Maharjan, N. Wai, A. Veksha, A. Giannis, T. M. Lim, and G. Lisak, J. Electroanal. Chem., 834, 94 (2019). 